International Small

Business Journal

\title{
Examining the effect of entre-tainment as a cultural influence on entrepreneurial intentions
}

\begin{tabular}{|c|c|}
\hline Journal: & International Small Business Journal \\
\hline Manuscript ID: & ISB-12-0258 \\
\hline Manuscript Type: & Full Paper \\
\hline Keywords: & $\begin{array}{l}\text { entrepreneurial intention, entre-tainment, culture, start-up skills, social } \\
\text { legitimacy }\end{array}$ \\
\hline Abstract: & $\begin{array}{l}\text { Little is known about the effect cultural media has in influencing attitudes } \\
\text { and behaviours towards entrepreneurship. In addressing this research gap } \\
\text { our paper employs a neologism - entre-tainment - defined as those } \\
\text { televisual media that stage and perform entrepreneurship and other } \\
\text { business-related activity for entertainment purposes. In doing so, we } \\
\text { examine the relationship between perceptions of entre-tainment and } \\
\text { entrepreneurial intent of university students, through administering a } \\
\text { survey instrument to test three hypotheses. We estimate a multiple } \\
\text { regression model using the Ordinary-Least-Squares (OLS). Our findings } \\
\text { lead us to conclude that there is a positive relationship between the skills } \\
\text { which the sample believe they ascertain when they watch 'entre-tainment', } \\
\text { and entrepreneurial intention. Furthermore, the social legitimacy they } \\
\text { attach to this cultural media has a similar positive effect, on their } \\
\text { entrepreneurial intention. Finally, the greater the social legitimacy attached } \\
\text { to 'entre-tainment' the stronger is the relationship between perceived skills } \\
\text { and entrepreneurial intention. Our discussion focuses on the broader } \\
\text { implications of these findings, in particular for policymakers who need to } \\
\text { be aware of the potential effects of entre-tainment in transmitting narrow } \\
\text { messages of what it means to behave entrepreneurially. }\end{array}$ \\
\hline
\end{tabular}

\section{SCHOLARONE \\ Manuscripts}




\title{
Examining the effect of entre-tainment as a cultural influence on entrepreneurial intentions
}

\begin{abstract}
Little is known about the effect cultural media has in influencing attitudes and behaviours towards entrepreneurship. In addressing this research gap our paper employs a neologism entre-tainment - defined as those televisual media that stage and perform entrepreneurship and other business-related activity for entertainment purposes. In doing so, we examine the relationship between perceptions of entre-tainment and entrepreneurial intent of university students, through administering a survey instrument to test three hypotheses. We estimate a multiple regression model using the Ordinary-Least-Squares (OLS). Our findings lead us to conclude that there is a positive relationship between the skills which the sample believe they ascertain when they watch 'entre-tainment', and entrepreneurial intention. Furthermore, the social legitimacy they attach to this cultural media has a similar positive effect, on their entrepreneurial intention. Finally, the greater the social legitimacy attached to 'entre-tainment' the stronger is the relationship between perceived skills and entrepreneurial intention. Our discussion focuses on the broader implications of these findings, in particular for policymakers who need to be aware of the potential effects of entre-tainment in transmitting narrow messages of what it means to behave entrepreneurially.
\end{abstract}

\section{Keywords}

Entrepreneurship, entrepreneurial intention, start-up skills, culture, entre-tainment, social legitimacy 


\section{Introduction}

Since the days of the robber barons - Vanderbilt, Rockefeller and Carnegie - famous entrepreneurs have been the focus of newspapers, books and film. Following the rise of what has become a global culture of enterprise in the early 1980s (Keat and Abercrombie, 1990), popular media have intensified this interest such that figures such as Richard Branson, Alan Sugar and Donald Trump have for many come to stand for 'the entrepreneur'. Doing entrepreneurship has even become the context for elaborate game shows such as Dragons' Den, where successful business people, with established entrepreneurial dynasties become celebrity entrepreneurs worthy of attention and respect.

Scholarly interest from within entrepreneurship in such entrepreneurially-focused popular culture has not been extensive. Studies have either drawn tentative empirical conclusions on how the media influences entrepreneurial behaviour from data excavated from general surveys (Hindle and Klyver, 2007; Levie et al., 2010), or focused on the representation of culture and media more directly from a cultural studies perspective (Boyle, 2008). There is an obvious practical imperative for more detailed research in this area: policy makers are interested in understanding the potential value of televisual entertainment in stimulating entrepreneurship (European-Commission, 2007). Theoretically there have been those that have emphasised the importance of the 'social situation' that entrepreneurs operate within, which includes 'what is done towards them, when they are constructing and developing businesses - how they interact, what sorts of symbols and discourses circulate within particular contexts' (Goss, 2008: 133). Televisual media would clearly form a cultural aspect of this context. Other studies (Audretch, 2007; Gavron, 1998) have highlighted the important role of ideologies in generating more entrepreneurially dynamic societies, and its potentially negative effects (Ogbor, 2000). Again, television is a conduit through which such ideologies can be communicated. 
The present study offers data derived from a detailed bespoke survey directly concerned with the influence of entrepreneurially specific cultural media for which we have coined a neologism: entre-tainment (Author reference). This we do in order to create a distinct conceptual and empirical object which we hope will act as a conceptual attractor (Steyaert, 2007). A key question in this research then is - if entrepreneurial culture, and our specific focus, entre-tainment, is indeed potentially transformative and generative of entrepreneurial ideology - how are we to know if and how individuals become more entrepreneurially oriented or skilled as a result of engaging with such cultural artefacts?

In the following analysis, we examine the skills individuals perceive to learn by watching Dragon's Den and the social legitimacy they attach to entre-tainment more generally. We make two assumptions (which also form the basis of our hypotheses). First, if a person thinks s/he has the necessary skills to start a business, they are more likely to do so. Second, this propensity is enhanced further if they also perceive entre-tainment as socially legitimate. That is, we seek to investigate if entre-tainment has an effect on these factors that influence entrepreneurial intention, which we understand as a commonly used proxy for understanding and predicting the degree of entrepreneurial activity (Engle et al., 2010; Thompson, 2009). In this we are treating skills and social legitimacy in a similar manner to self-efficacy and opinions of significant others, which have been shown to be strong predictors of entrepreneurial intentions (Armitage and Conner, 2001; Conner and Armitage, 1998).

Our empirical contribution adds depth to the breadth already provided through analyses of generic surveys such as the Global Entrepreneurship Monitor (GEM) (Hindle and Klyver, 2007; Levie et al., 2010). These previous studies (described more fully below) adopt a descriptive approach. Through the regressions run on our data we are able to infer relationships between social legitimacy, entrepreneurial skills and intentions in more detail. Specifically we differentiate between televisual entertainment based media which depicts entrepreneurial activity, from the 
study of other cultural signifiers such as newspapers (Nicholson and Anderson, 2005; Radu and Redien-Collot. 2008), which are amalgamated in the more generic studies (Hindle and Klyver, 2007; Levie et al., 2010). Televisual media are dominant cultural forms that serve to transmit enterprise discourses and ideology (Ogbor, 2000; Rehn, 2008), yet few studies have sought to empirically investigate the effect entre-tainment might have on beliefs/attitudes (i.e. social legitimacy), skills and behaviour. Moreover, the discussion that emerges from our empirical findings on the influence of entre-tainment on entrepreneurial behaviours serves to push this emerging interdisciplinary dialogue along somewhat. Our broader aim is to use the empirical study as a sounding board to make a conceptual contribution to understanding the intersection of entrepreneurship and culture. More practically, our research builds understanding about the effectiveness, or otherwise, of entre-tainment as a means by which to transfer or reinforce entrepreneurial skills.

The rest of the paper more thoroughly embeds the notion of entre-tainment with existing research on culture and entrepreneurship, and draws on concepts and theories from the social sciences and cultural studies to ground the neologism. We then discuss the methodological procedures used in designing and administering the survey, and analysing the survey data, before presenting the findings in more detail. In the discussion, we discuss the contribution of this research in more detail and elaborate further about other empirical questions of interest concerning the intersection of televisual culture and the study of entrepreneurship. Finally, we explore some of the theoretical and practical implications for entrepreneurship more generally and advance potential avenues for future research. 


\section{Literature review: entre-tainment and entrepreneurial behaviour}

Our interest in culture, a large and very well swept intellectual corner - to misapply the object of Geertz's useful metaphor (1973: 5) - is mainly focused at popular culture. Of course, popular culture is a contested term (Storey, 2006), but as we are mainly concerned with the role of specific television programmes (e.g. Dragons' Den) the theoretical nuances debated by cultural theorists are not pertinent. It is not our object of analysis, and hence we see popular culture descriptively and plainly as culture - in the sense of 'signifying practices'; the production and consumption of art, writing and so forth - that is 'widely favoured or well liked by many people' (Storey, 2006: 1, 4): a synonym for mass culture.

That said it is worth briefly understanding how entrepreneurship has approached culture more generally in order to achieve our subsidiary aim of using entre-tainment as a conceptual attractor to examine the intersection of culture and entrepreneurship more broadly. The underlying approach to culture adopted here is to see it as a process of symbolic and interpretive action manifest in a particular way of life. Thus, despite the methodological reductionism applied in the empirical analysis reported in this paper, we are keen to situate our broader discussion of the intersection of culture and entrepreneurship in a view that accepts that 'culture is not a power, something to which social events, behaviours, institutions, or processes can be causally attributed; it is a context, something within which they can be intelligibly - that is, thickly described.' (Geertz, 1973: 14)

What this means is that when we attribute entre-tainment as influencing, or not, individual values, belief and actions, what we are actually claiming is that as individuals watch, think about and discuss such cultural artefacts or 'signs', they are making complex context-bound and relationally contingent interpretations based on their place in their culture; their particular way of life. How knowledge about business and entrepreneurial skills and the perceived social legitimacy 
of entre-tainment, our specific empirical foci in this paper, are transmitted or signified need to be seen against this conceptual background. Thus, culture, in both these senses (descriptive and contextual), intersect in our broader purpose, if not our empirical contribution.

Turning now to our specific focus - popular culture and entrepreneurial behaviour - there have only been limited attempts to research the connections between these phenomena. Something that the European Commission, Enterprise and Industry Directorate-General acknowledged: 'so far not much is known about the influence of the media on occupational choices or on the attitudes towards entrepreneurship' (2007: 4). It is assumed here that entrepreneurship as it is represented and signified by popular culture has strong potential for promoting enterprise, with policy-makers seeking to see an explicit move away from depicting entrepreneurs as 'crooks and villains' (European-Commission, 2007: 34), and towards representations showing entrepreneurship as a worthwhile and respectable career choice. There has been some research however.

Hang and Weezel's (2007) review of media and entrepreneurship highlight three areas where research has concentrated. Firstly, there have been studies of entrepreneurship as a process within the media industries itself (Kelly and Boyle, 2011). Secondly, entrepreneurship as it is represented in, and disseminated through the media. Studies such as those by Radu and RedienCollot (2008) and Nicholson and Anderson (2005) analyse popular press discourse with a view to investigating how entrepreneurs, and the entrepreneurial act is represented and socially constructed (Anderson and Warren, 2011). Boyle (2009) has tracked the change in business and entrepreneurial representations on British television, and notes that there has been an increase in the number of factual television programmes about business and entrepreneurship. These two themes are peripheral to our interests, and do not address the third theme that Hang and Weezel identify, that is, the role that media plays in influencing entrepreneurial activity. Here they 
conclude that 'few efforts have been made to investigate how media affect the entrepreneurship phenomena' (Hang and Weezel, 2007: 17).

There have been studies that have addressed the broader relationship between business and popular culture. In particular Rehn (2008) - who coins a more encompassing neologism, 'econotainment' (2008: 769), referring to the more general depiction of business in popular culture makes an important theoretical contribution. Though not focused on entrepreneurship, his recognition that popular culture should not be seen as uni-directional, with viewers consuming culture solely as it is intended by producers, as a causally attributed power effecting behaviour, goes to the core of any attempt to understand how television programmes like Dragons' Den might influence behaviour. Audience (the viewer, reader, or listener) plays an active role in interpreting and mediating any 'messages' in the context of their particular way of life. Thus, to be clear, a middle-class, business management graduate, who has aspirations to start a business and is seed-funded by wealthy entrepreneur parents will likely view such programmes differently from a working-class, non-university educated mechanic who after serving an apprenticeship, decided to work for himself. We bring our own values and ideas to whatever we read and watch, and what goes on in this mediation process is as much to do about our own values (such as the influence of family, friendship, social background, education etc.) as it is to do about what the media presents. Rehn (2008) argues that this two-way relationship is over-looked in business studies, and calls for more academic scrutiny into the influence that popular culture has upon the economy.

Work by Raymond Boyle and colleagues, based on an Arts and Humanities Research Council (AHRC) funded study addresses the link between popular culture and entrepreneurship. Specifically, in relation to our aims, Boyle and Kelly (2012: 3) asks audiences about 'their levels of engagement with business on television, their knowledge and understanding of the term entrepreneur and the relationship between television representations of business and 
entrepreneurship and the experiences that audiences themselves may bring to these programmes' using an audience research methodology. They found that responses varied according to audience stages of entrepreneurial activity and experience. More established business owners view 'entre-tainment' media as entertaining and humorous, and nascent entrepreneurs see it as more a positive educational influence, in terms of the skills and business 'tips' they may pick up.

Finally there has been two important but limited studies of Global Entrepreneurship Monitor (GEM) data addressing the influence of the 'media' on entrepreneurial behaviour (Hindle and Klyver, 2007; Levie et al., 2010). Hindle and Klyver (2007) used the GEM data to track 'stories about successful entrepreneurs, conveyed in mass media' (2007: 217). They argued that mass media are only capable of reinforcing existing audience values, and are not capable of changing or inverting such values. In short, this means that such success stories in the media appeared only to encourage those already taking part in entrepreneurial activity. However, this conclusion is based on rather a narrow conceptualisation of mass media based on a single question related to the concept of role models and stories about successful entrepreneurs: 'In your country, do the public media often have stories about successful new businesses?' Levie et al.'s (2010) analysis, using a longitudinal data set combining the UK GEM 2009 and a media-specific follow-up survey, similarly found that 'media coverage tends to reinforce existing values and desires rather than create new or different values' (2010: 3). This study, the most extensive and specific to date, concluded that TV business reality programmes tend not to directly trigger actual entrepreneurial intentions or action and the discernible effects are considerably lower than that of family, friends, work colleagues and education and training in university or college. However, they do have 'a positive effect on social norms and values and thereby influence both the desirability and feasibility of entrepreneurship. In this sense, they do, albeit indirectly, influence actual patterns of entrepreneurship.' (2010: 3). 
Our study looks to deepen the content and further theoretical discussion when addressing culture and entrepreneurship. Both studies described above are limited by their use of a narrow 'media stories' measures for culture. They perform only a descriptive analysis, whereas the current study uses more detailed psychometric measures and an inferential analysis. In short, compared to the breadth achieved by these previous studies, the empirical contribution of the research reported in this paper adds a degree of depth in terms of the content of 'culture'. We describe the details of this content about culture and entre-tainment elicited by our survey after explaining our hypotheses, which builds on the assumption about the link between skills, social legitimacy and entrepreneurial intention, sketched above.

\section{Hypothesis development}

The impact of perceived skills on entrepreneurial intention

Radu and Redien-Collot (2008) argue that the media impact on efficacy and control beliefs about the personal skills required to become a successful entrepreneur may increase or decrease feasibility perceptions. Hence, this implies that programmes such as Dragons' Den have the potential to shape feasibility expectation positively or negatively. This is also reflected in how (Author reference) emphasised that entre-tainment programmes, through their 'reality' format, are essentially etiquette guides, about how to be and behave in particular social contexts. Dragons' Den shows people - both participant and viewer - what, and what not, to do in order to be a successful entrepreneur' (2010: 185-186). Kelly and Boyle (2011) argue something similar when they conclude that the combined entertainment/education focus of such programmes transmits quite detailed information about the fundamentals of business start-up. Consequently, our study seeks to explore whether the tacit transfer of knowledge and skill through viewing entretainment programmes such as Dragons' Den results in increased entrepreneurial intention. Thus our first hypothesis asks if: 
H1 - There is a positive relationship between the skills which individuals believe they ascertain when watching 'entre-tainment' and entrepreneurial intention.

\section{The impact of social legitimacy on EI}

Studies by Rehn (2008) and Boyle (2009; Boyle and Kelly, 2012) imply a strong link between the way business media is produced, interpreted and consumed and perceptions of legitimacy and significance among viewers. Moreover, research into entrepreneurial intentions shows that the extent to which individuals feel motivated to pursue entrepreneurial opportunities will be reflected in their belief that entrepreneurship is socially acceptable and entrepreneurs themselves are respected members of the community (Author reference; Liñan et al., 2011; Reynolds et al., 2000). Studies showing that countries value entrepreneurship differently demonstrate variability in perceived social legitimacy. Fayolle et al. (2010), for instance, has shown that American culture values entrepreneurship more than the French or Scandinavian. Positive cultural representations of entrepreneurship are likely to both reflect and reproduce such perceptions. As well as national and regional variability we can assume that individuals will differ in the manner in which they internalise and interpret entre-tainment based on their own backgrounds, values and beliefs. This variability of social legitimacy is also apparent in a recent study by Dodd et al. (forthcoming). They explored the positive and negative connotations associated with metaphors of entrepreneurship across five European countries and found that entrepreneurship was almost universally admired. However, they too found variation between countries, with the UK and Ireland having a more positive outlook than, for instance, Greece. As popular media representations will likely play an important role in creating and reproducing such metaphors (Langowitz and Morgan, 2002), we can see that 'the media may render entrepreneurship as more or less desirable, due to [its] impact on acceptability and legitimacy beliefs about entrepreneurs 
and their day-to-day actions' (Radu and Redien-Collot, 2008: 261). We view entre-tainment as a subset of popular media that will tend to positively impact on the degree of acceptance and legitimacy that individuals attach to both the entrepreneur and the practice of entrepreneuring in societies. Of course, this assumption also underpins political interest in encouraging positive popular representations of enterprise (European-Commission, 2007). Consequently, given that the social legitimacy of entre-tainment for its viewers forms a cornerstone of the present study, our second hypothesis states that:

$\mathrm{H} 2$ - There is a positive relationship between the associated social legitimacy attached to 'entre-tainment' and entrepreneurial intention.

The moderating effect of social legitimacy on the effect of perceived skills

This paper is based on the premise that social legitimacy attached to entre-tainment facilitates the formation of entrepreneurial intentions by enhancing the effect of perceived skills on entrepreneurial intention. In addition, we argue that if an individual perceives entre-tainment as socially legitimate and worthwhile, they will be more receptive to its content. Subsequently, they perceive that when they view Dragon's Den they are learning something of value, even though they may not be able to determine exactly what they are learning. Rather, learning occurs implicitly through a process which Claxton (1998) refers to as learning through 'osmosis'. This learning osmosis demonstrates to viewers how entrepreneurship should be done, moreso than those who do not rate such programmes or further still, who believe they are not beneficial for society at large. In essence, we view entre-tainment as the stage where 'entrepreneuring' is performed in front of a captive audience. The degree to which viewers value what they observe may also influence their assessment of perceived skills developed. Therefore, given the 
hypotheses advanced above we further predict that these variables will have a mutually beneficial affect on entrepreneurial intention. Therefore, we propose that:

H3 - The greater the social legitimacy attached to 'entre-tainment', the stronger is the relationship between perceived skills and entrepreneurial intention.

\section{Data collection and measures}

Data collection

The data were collected by administering a survey instrument to all students at a UK university. We acknowledge that prior studies on entrepreneurial intentions are often criticised for being overly reliant on data collected from university students (McGee et al., 2009). Nonetheless we purposely chose to employ the university student as our unit of analysis because they are the focus of particular policy interest: the highly educated young. It is students in higher education that carry the hopes of those that seek to build more entrepreneurially dynamic societies (Gavron, 1998). It is these individuals that are increasingly exposed to enterprise pedagogy. And, with continuing structural shifts in labour markets and declining numbers and quality of traditional employment there is an expectation that forms of self-employment will become increasingly important to highly skilled graduates (European Commission, 2007).

Prior to administering the survey, care was taken to pilot the instrument with a small group of students, researchers and other experts who offered feedback and advice. The survey was emailed to the student population in November 2010 (a follow-up reminder email was sent in December 2010), totalling 21,218 across UG and PG levels, including resident UK students and International students. 960 responses were received, a response rate of $4.5 \%$.

In order to examine potential sampling bias, we employed archival analysis (Rogelberg and Stanton, 2007) to compare key characteristics of the respondents (gender, student discipline, 


\section{Measures}

Response variable The response variable in the analysis is entrepreneurial intention which we measure using Thompson's (2009) Individual Entrepreneurial Intention Scale (IEIS). We considered this six-item scale to be more versatile for the purposes of the present study than other available measurements of entrepreneurial intent (see Krueger et al., 2000; Lee and Wong, 2004; Chen et al., 1998), because it captures not only an individual's interest in entrepreneurship as such, but also their involvement in different activities signalling a serious interest in starting a business. Appendix 1 provides a full list of scale items.

Explanatory variables The first explanatory variable in the analysis is the skills that the respondent perceives to learn by watching Dragon's Den. It is assumed that when viewing Dragon's Den, the viewer is exposed to key entrepreneurial behaviours (such as communicating a business idea, evaluating risk, and so on) imparting tacit knowledge, and potentially resulting in learning taking place. We considered a range of skills that viewers may possibly observe on the programme and a list of eleven Likert-style items (Appendix 1) was developed accordingly. It is important to note that this study is measuring the perception of, rather than actual skills learnt, and 
we share the assumptions made by those investigating entrepreneurial self-efficacy (Chen et al., 1998; Wilson et al., 2007), in that we consider that the higher the agreement with perceived skill the higher also entrepreneurial intent.

The second explanatory variable is the perceived social legitimacy of entre-tainment which this study measures with four items developed by the authors (Appendix 1). The items in this scale relate to the extent to which participants consider that entre-tainment is a positive influence in British society in terms of encouraging entrepreneurship and positively impacting the economy. It is considered that agreement with these items indicate a degree of acceptance and legitimacy attached to the phenomenon of entre-tainment.

Control variables The analysis includes a number of control variables in order to adjust the model for factors that might influence the relationships between the explanatory and the response variables. The first control variable is the respondent's sex which is included in the regression model as a dummy with female coded as 1 . The second control measure is the student's country of origin, measured as a dummy where domestic students are coded as 0 and international students as 1 . The third control variable distinguishes between undergraduate and postgraduate students so that postgraduate students are coded as 1 in the dummy. The fourth control variable captures whether the respondent knows an entrepreneur personally. The fifth and the final control measure denotes whether the respondent has studied a module or course in enterprise, entrepreneurship or small business.

Inclusion of these particular control variables was determined by both good practice evidence from previous studies and also common-sense considerations. First, it is acknowledged in the literature that females have both a lower propensity for embarking on entrepreneurship and lower entrepreneurial self-efficacy (Wilson et al., 2003, 2007; Kickul et al., 2008; Chen et al., 1998). It was therefore considered that gender may affect entrepreneurial intention as well as 
perceived skill variables. Second, we thought it prudent, following previous research discussed above (e.g. Fayolle et al., 2010) to consider the country of origin as language and other cultural factors will influence the manner in which entre-tainment is interpreted and how subsequent opinions are formed. Furthermore, despite residing in the UK at the time the study was conducted we assume that exposure to 'entre-tainment' may be less for international students than UK students. Third, distinguishing between undergraduate and postgraduate was deemed sensible as it was considered that knowledge, maturity and attitudes might be affected with increased exposure to further education, which in turn may influence the relationships between our variables. Finally, knowing an entrepreneur and studying entrepreneurship has been shown to correlate with entrepreneurial intent (Cox et al., 2002; Thompson, 2009), thus justifying inclusion of the fourth and fifth dummy variables.

\section{Factor analysis and descriptive statistics}

The response variable and both explanatory variables constitute factors that comprise multiple items. Before computing index scores and proceeding to regression analysis, we subjected the three measurement scales to a purification process. An exploratory principal components analysis with direct oblimin rotation results in three factors that explain $59 \%$ of the variance in the data. The rotated solution shows that all eleven items measuring perceived skills load on the first factor (loadings $0.66-0.85$ ), the four items that measure the social legitimacy of entre-tainment load on the second factor (loadings $0.77-0.82$ ) and all items that belong to the entrepreneurial intention scale load on the third factor (loadings 0.65-0.89). No item cross-loads on another factor with a loading higher than 0.15 .

A subsequently performed confirmatory factor analysis (CFA) suggested the elimination of one item in the entrepreneurial intention scale due to a low loading $(<0.5)$, and one item in the perceived skills scale due to heavy correlations with other items in the scale (Appendix 1). With 
these modifications, all remaining indicators load significantly $(0.1 \%$ level $)$ on their intended constructs and the conventional fit indices suggest a satisfactory fit between the model and the data: the comparative fit index (CFI) is 0.954 which meets the recommended minimum of 0.95 ; the root mean square error of approximation (RMSEA) is 0.056, which is below the recommended maximum of .06; and the standardized root mean square residual (SRMR) is 0.039, which is clearly below the recommended maximum of 0.08 (Hu and Bentler, 1999).

Table 1 summarises the results of the CFA and provides a number of additional indices for scale reliability. For all three measurement scales, the composite reliability and Cronbach alpha scores are clearly above the recommended threshold of 0.7 (Chin, 1998; Nunnally, 1978). Similarly, the Average Variance Extracted (AVE) values for all constructs exceeding the recommended minimum of 0.5 suggests that the indicators explain more of each construct than other, external influences (Fornell and Larcker, 1981) which indicates good convergent validity. The AVE also serve as a measure of discriminant validity: if the square root of a construct's AVE exceeds its correlation with the other latent constructs in the CFA model, the model has good discriminant validity (Fornell and Larcker, 1981). The present CFA fulfils this criterion: the square roots of the AVE scores range from 0.72 to 0.74 whilst the respective correlation coefficients range from 0.33 to 0.60 . Against this backdrop, we conclude satisfactory reliability and validity for the measurement scales and compute indices for each of them by averaging the item scores.

Table 1 about here

Table 2 displays the means, standard deviations, and inter-correlations between all variables in the regression model. The correlations are moderate and thus do not suggest serious multicollinearity. The Variation Inflation Factor (VIF) scores in the regression analysis support 
this conclusion, as the highest VIF score of 1.6 is clearly below the conventional threshold of 10 for serious multicollinearity.

Table 2 about here

\section{Analysis}

For hypothesis testing, we estimate a multiple regression model using the Ordinary-LeastSquares (OLS) estimator with heteroscedasticity-consistent (robust) standard errors. The model estimation process involves the following three steps.

The first estimation step regresses entrepreneurial intentions on both explanatory variables in order to examine the direct effects of these variables on the dependent variable without additional covariates influencing the results (Model 1 in Table 3). The estimates show that both explanatory variables have a positive and significant effect on entrepreneurial intentions. Hence, Hypotheses 1 and 2 receive support.

Before proceeding to the next step, we ensured that these significant effects are not due to common method variance, which is a potential problem with these data because the data for all variables in each observation were collected with the same research instrument at the same time using the same informant. In order to control for the effect of common method variance, we estimated Model 1 as a structural equation model with all constructs modelled as latent variables and included a single unmeasured latent method factor in the model specification. This procedure controls for systematic variance among the items associated with the three latent variables (entrepreneurial intention, perceived skills and social legitimacy) in the model by adding a first-order factor with all of the said items as indicators (Podsakoff et al., 2003). The model has satisfactory fit (CFI: 0.957; RMSEA: 0.057; SRMR: 0.031) and the maximum-likelihood estimates are comparable with Model 1 in Table 3 even in the presence of the method factor: perceived 
skills has a positive effect on entrepreneurial intentions at the $0.1 \%$ significance level and the coefficient for social legitimacy is positive and significant at the $5 \%$ level. Therefore, we deem it safe to continue to further steps of the regression analysis, which is a more flexible analytical technique for estimating interactions between continuous variables than structural equation modelling.

Table 3 about here

The second step in the estimation process adds the interaction between the two explanatory variables into the model specification. Model 2 in Table 3 shows that the interaction term is positive and significant. The positive interaction term implies that when social legitimacy is high, the effect of perceived skills on entrepreneurial intention becomes stronger than when social legitimacy is low.

Before graphing the interaction effect, we added the control variables to the equation, in order to estimate whether they modify the previously estimated relationships. The estimates in Model 3 in Table 3 show that the previously estimated effects remain significant also in the presence of the control variables.

Finally, we graphed the interaction effect based on the estimates in Model 3 (Table 3). Figure 1 illustrates the marginal effect of perceived skills at different levels of social legitimacy. Since the variables are mean-centred, social legitimacy is at its sample mean when its value is zero. The illustration shows that the marginal effect of perceived skills is higher if the person also rates the social legitimacy of entre-tainment highly. An examination of the confidence intervals reveals that perceived skills have a statistically significant and positive effect on entrepreneurial intention only when social legitimacy is greater or equal to approximately 1.3 units below its sample mean (i.e., greater or equal to 2.3 on a scale from 1 to 5). In other words, at low levels of social 
legitimacy perceived skills do not exert a significant effect on entrepreneurial intention. This finding supports Hypothesis 3.

Figure 1 about here

\section{Discussion}

It is evident that individuals who watch such television programmes perceive that they are gaining pedagogic value and as a result have more positive perceptions of an entrepreneurial career (H1). Through observing the staged successes and failures of contestants the viewer believes that they learn effective ways of doing entrepreneurship, such as communicating business ideas, evaluating risk and how to negotiate effectively.

What though are they really learning? These programmes are aired primarily to entertain. They are also highly selective in the sorts of business activity depicted. However, this does not imply that they are not of value in terms of the implicit knowledge accrued, as our findings have shown. Nevertheless, formulating and delivering a venture capital pitch is not an everyday entrepreneurial practice (Jarvis, 2006), which is a core activity in Dragons' Den. In addition, these programmes advocate and promote a highly aspirational form of entrepreneurship that focuses on high growth and profit as opposed to the more modest income generating reality for the vast majority of businesses. As a result, if entre-tainment is taken seriously as a pedagogic vehicle, the risk is that skewed and partial set of skills may be developed among its viewers.

This study has shown that if individuals perceive that these programmes are socially legitimate then they will be more pre-disposed to launching a business (H2). In this context, these programmes provide a platform for the promotion of the entrepreneurial ideal. Thus entretainment, like all cultural artefacts, is a vehicle for the transmission of ideologies, beliefs and values (Ogbor, 2000), which in this case positively influences entrepreneurial intent. In other 
words, these programmes, take a strong, positive stance in support of the legitimacy of a particular form of entrepreneurship, by judging people on whether or not they fit an entrepreneurial ideal. Furthermore, we suggest that by showcasing a distinct dichotomy between winners and losers, entre-tainment celebrates a certain truncated set of socially legitimate behaviours. The viewer, that is the potential entrepreneur, is only presented a narrow window with which to view what it means to be successful. As a result, those who are equipped with both the 'right' personality and idea to succeed are considered winners, whereas those who do not fit the entrepreneurial ideal are portrayed as losers, whose lack of mastery is often ridiculed. Moreover, these hyperbolic, polar distinctions between winners and losers misrepresent what is in fact a matter of degree. The reality of entrepreneurship is that individuals succeed to varying extents. Failure is often the result of a number of culminating factors, internal and external which may or may not include idea viability and personal ability (Cope, 2010).

Building on the supported hypothesis $(\mathrm{H} 2)$ that positive perceptions of social legitimacy of entre-tainment have a positive effect on entrepreneurial intention, our final hypothesis (H3) explored the moderating effect of social legitimacy on the effect of perceived skills. That is, do the skills learnt by watching Dragon's Den have a stronger effect on entrepreneurial intent for those who think that entre-tainment is both positive for entrepreneurship and the UK economy as a whole, and believe that celebrity entrepreneurs encourage entrepreneurial action? Our analysis shows this to be the case.

Though not surprising that there are individuals in our sample who show such enthusiasm for both the values and subsequent learning gained through watching Dragons' Den, do we risk producing a group of enterprising neophytes who may well be surprised (should they actually start a business) when faced with the mundane realities of everyday entrepreneurial life? If programme makers are going to conflate entertaining with educating (Kelly and Boyle, 2011) then policymakers need to be aware of the implications of merging these activities and the 


\section{Conclusion}

It is evident from our study that entre-tainment plays a significant role in shaping attitudes and intentions towards entrepreneurship. However, we acknowledge that entretainment reflects only a small part of wider cultural influences and our study truncates culture to a uni-directional phenomenon due to the methodological reductionism employed. The research is also limited by its narrow geographical and sectoral focus, set as it is in a UK regional university. Clearly future research seeking to extend the empirical scope should examine both additional geographical locations (UK regions as well as country comparisons) and also draw samples from different stages of the entrepreneurial process (e.g. nascent, established, failed entrepreneurs). In investigating further regional variation on the impact of entre-tainment we will be able to contribute to the debates surrounding lagging and dynamic regions (e.g. Total Entrepreneurial Activity, TEA, in GEM). Similarly, by applying the survey instrument to individuals at different stages in the entrepreneurial process, as initiated by Hindle and Klyver (2007) and Levie et al. (2010) we will gain insights into the variable influences of culture on entrepreneurial activity.

As our initial discussion of culture and its interpretative complexity implies (Geertz, 1973), the current study has also been limited by its methodological scope. That is, as is the case 
in much entrepreneurship research, in understanding the intersection of culture and entrepreneurship a greater range of research tools are required (Hindle, 2004). For instance, audience studies, focus groups, viewing diaries, interviews etc. are all effective tools to capture greater degrees of interpretative insight with which to complement the quantitative findings of this study and prior work (Hindle and Klyver, 2007; Levie et al., 2010). Given the ubiquity and rise of business entertainment formats, the influence of popular culture on entrepreneurship should be taken more seriously. In order to do this more sophisticated and interdisciplinary approaches are needed. Ideas and concepts from cultural theorists, culture and media studies, sociologists and anthropologists should all be more readily applied. Entre-tainment offers potential in this regard, acting as a conceptual attractor by which to address broader questions of culture and entrepreneurship in the field.

\section{References}

Anderson A and Warren L (2011) The entrepreneur as hero and jester: Enacting the entrepreneurial discourse, International Small Business Journal 29(6): 589-609.

Armitage CJ and Conner M (2001) Efficacy of the theory of planned behaviour: a meta-analytic review. British Journal of Social Psychology 40: 471-499.

Audretsch D (2007) The Entrepreneurial Society. Oxford: Oxford University Press.

Boyle R (2008) From Troubleshooter to The Apprentice: the changing face of business on British television. Media, Culture and Society 30(3): 415-424.

Boyle R (2009) The rise of the business entertainment format on British Television. In: Moran A(ed) TV Formats Worldwide: Localising Global Programs. London: Intellect.

Boyle R and Kelly LW (2012) The Television Entrepreneurs: Social Change and Public Understanding of Business. Farnham: Ashgate.

Chin WW (1998) The partial least squares approach to structural equation modeling. In: Marcoulides GA (ed), Modern Methods in Business Research. Hillsdale, NJ: Earlbaum, pp.295-336 Claxton G (1998) Hare Brain, Tortoise Mind. London: Fourth Estate. 
Conner M and Armitage CJ (1998) Extending the theory of planned behaviour: a review and avenue for further research. Journal of Applied Social Psychology 28(15): 1429-1464.

Cope J (2010) Entrepreneurial learning from failure: An interpretative phenomenological analysis. Journal of Business Venturing 26(6): 604-623.

Cox L, Mueller S and Moss S (2002) The impact of entrepreneurship education on entrepreneurial self-efficacy. International Journal of Entrepreneurship Education 1(2): 229-247.

Chen CC, Greene PG and Crick A (1998) Does entrepreneurial self-efficacy distinguish entrepreneurs from managers? Journal of Business Venturing 13: 295-316.

Drakopoulou Dodd S, Jack S and Anderson AR (2012) From admiration to abhorrence; the contentious appeal of entrepreneurship across Europe. Entrepreneurship and Regional Development in press.

European-Commission (2007). Report of the Expert Group: Promoting Entrepreneurship on TV and in other audio-visual media, available at: http://ec.europa.eu/enterprise/policies/sme/files/support measures/av/media report en.p df (accessed: 20/11/2009).

Engle RL, Dimitriadi N, Gavidia JV, Schlaegel C, Delanoe S, Alvarado I, He X, Buame S and Wolff B (2010) Entrepreneurial intent: A twelve-country evaluation of Ajzen's model of planned behaviour. International Journal of Entrepreneurial Behaviour and Research 16(1): 35 - 57.

Fayolle A, Basso O and Bouchard V (2010) Three levels of culture and firms' entrepreneurial orientation: A research agenda. Entrepreneurship and Regional Development 22(7/8): 707-730.

Fornell C and Larcker DF (1981) Evaluating structural equation models with unobservable variables and measurement error. Journal of Marketing Research 18(1): 39-50.

Gavron R. (1998) The Entrepreneurial Society. London Institute for Public Policy Research.

Geertz C (1973) The Interpretation of Cultures. New York: Basic Books.

Goss D (2008) Enterprise ritual: A theory of entrepreneurial emotion and exchange. British Journal of Management 19(2): 120-137.

Hang M and Weezel AV (2007) Media and entrepreneurship: What do we know and where should we go? Journal of Media Business Studies 4(1): 51-70. 
Hindle K (2004) Choosing qualitative methods for entrepreneurial cognition research: A canonical development approach. Entrepreneurship, Theory and Practice 28(6): 575-607.

Hindle K and Klyver K (2007) Exploring the relationship between media coverage and participation in entrepreneurship: Initial global evidence and research implications. International Entrepreneurship and Management Journal 3(2): 217-242.

Hu LT and Bentler PM (1995) Evaluating model fit. In: Hoyle RH (ed) Structural Equation Modelling Thousand Oaks: Sage, pp.76-99.

Hu L and Bentler PM (1999) Cutoff criteria for fit indexes in covariance structure analysis: Conventional criteria versus new alternatives. Structural Equation Modelling: A Multidisciplinary Journal 6(1): 1-55.

Jarvis R (2006) Finance and the small firm. In: Carter S and Jones-Evans D (eds) Enterprise and Small Business: Principles, Practice and Policy (2nd ed) Harlow: Prentice Hall, pp.338-356.

Keat R and Abercrombie N (1990) Enterprise Culture. London: Routledge.

Kelly L and Boyle R (2011) Business on television: continuity, change and risk in the development of television's ‘business entertainment format'. Television and New Media 12(3): 228-247.

Kickul J, Wilson F, Marlino D and Barbosa SD (2008) Are misalignments of perceptions and self-efficacy causing gender gaps in entrepreneurial intentions among our nations' teens? Journal of Small Business and Enterprise Development 15(2): 321-335.

Krueger NF, Reilly MD and Carsrud AL (2000) Entrepreneurial intentions: A competing models approach. Journal of Business Venturing 15(5/6): 411-432.

Langowitz NS and Morgan C (2002) Women entrepreneurs; the message in the media, the word on women entrepreneurs from 1996-2000. Paper presented at the Babson Conference, Boulder, Colorado.

Lee SH and PK Wong (2004) An exploratory study of technopreneurial intention: A career anchor perspective. Journal of Business Venturing 19(1): 7-28.

Leitch C, McMullan M and Harrison RT (2012) The development of entrepreneurial leadership: The role of human, social and institutional capital. British Journal of Management (forthcoming). 
Levie J, Hart M and Karim MS (2010) Impact of media on entrepreneurial intentions and actions. Global Entrepreneurship Monitor/BIS (accessed 15.5.12 http://www.bis.gov.uk/assets/biscore/enterprise/docs/I/11-773-impact-of-mediaentrepreneurial-intentions-actions ).

Liñan F, Urbano D and Guerrero M (2011) Regional variations in entrepreneurial cognitions: start-up intentions of university students in Spain. Entrepreneurship and Regional Development 23(3-4): 187-215.

McGee JE, Peterson M, Mueller SL and Sequeira JM (2009) Entrepreneurial self-efficacy: Refining the measure. Entrepreneurship Theory and Practice 33(4): 965-988.

Nicholson L and Anderson AR (2005) News and nuances of the entrepreneurial myth and metaphor: Linguistic games in entrepreneurial sense-making and sense-giving. Entrepreneurship Theory and Practice 29(2): 153-172.

Nunnally J (1978) Psychometric theory. New York: McGraw-Hill.

Ogbor JO (2000) Mythicizing and reification in entrepreneurial discourse: Ideology critique of entrepreneurial studies. Journal of Management Studies 37(5): 605-635.

Podsakoff PM, MacKenzie SB, Lee J and Podsakoff NP (2003) Common method biases in behavioral research: A critical review of the literature and recommended remedies. Journal of Applied Psychology 88(5): 879-903.

Radu M and Collot RR (2008)The social representation of entrepreneurs in the French press: Desirable and feasible models. International Small Business Journal 26(3): 259-298.

Rehn A (2008) Pop (culture) goes the organization: On highbrow, lowbrow and hybrids in studying popular culture. Organization 15(5): 765-783.

Reynolds PD, Hay M, Bygrave WD, Camp M and Autio E (2000) Global Entrepreneurship Monitor 2000 executive report. Kauffman Center for Entrepreneurial Leadership at the Ewing Kaufman Foundation. [Download: www.gemconsortium.org]

Rogelberg SG and Stanton JM (2007) Understanding and dealing with organizational survey nonresponse. Organizational Research Methods 10: 195 -209.

Scherer RF, Adams JS, Carley SS and Wiebe FA (1989) Role model performance effects on development of entrepreneurial career preference. Entrepreneurship Theory and Practice 13(3): 5371. 
Steyaert C (2007) 'Entrepreneuring' as a conceptual attractor? A review of process theories in 20 years of entrepreneurship studies. Entrepreneurship and Regional Development 19(6): 453-477.

Storey J ( 2006) Cultural Theory and Popular Culture: An Introduction. Harlow: Prentice Hall.

Thompson ER (2009) Individual entrepreneurial intent: Construct clarification and development of an internationally reliable metric. Entrepreneurship Theory and Practice 33(3): 669-694.

Wilson F, Kickul J and Marlino D (2007) Gender, entrepreneurial self efficacy and entrepreneurial career intentions: implications for entrepreneurship education. Entrepreneurship, Theory and Practice 31(3): 387-406. 


\section{APPENDIX 1: Construct variables}

Entrepreneurial intention

(Thinking of yourself, how true or untrue is it that you:)

Intend to set up a company in the future

Never search for business start-up opportunities (R)

Are saving money to start a business

Do not read books on how to set up a business (R)

Have no plans to launch your own company $(R)$

Spend time learning about starting a business

Perceived skills learnt by watching an episode of Dragon's Den

I learn about how to generate business ideas

I learn about how to communicate business ideas

I learn about how to commercialise business ideas

I learn about business operations

I learn about people management

I learn about how to network

I learn about how to negotiate

I learn about how to grow a business

I learn about how to evaluate risk

I learn about the financial aspects of business

I learn about the marketing aspects of business

Social legitimacy of entre-tainment

'Celebrity entrepreneurs' have a positive impact on the British economy

Programmes like the Dragon's Den and The Apprentice have a positive impact on the British economy

Programmes like the Dragon's Den and The Apprentice encourage entreprenership

‘Celebrity entrepreneurs' encourage entrepreneurship

Note: Italicised items were removed in the course of the scale purification process. 


\section{Table 1}

Confirmatory factor analysis

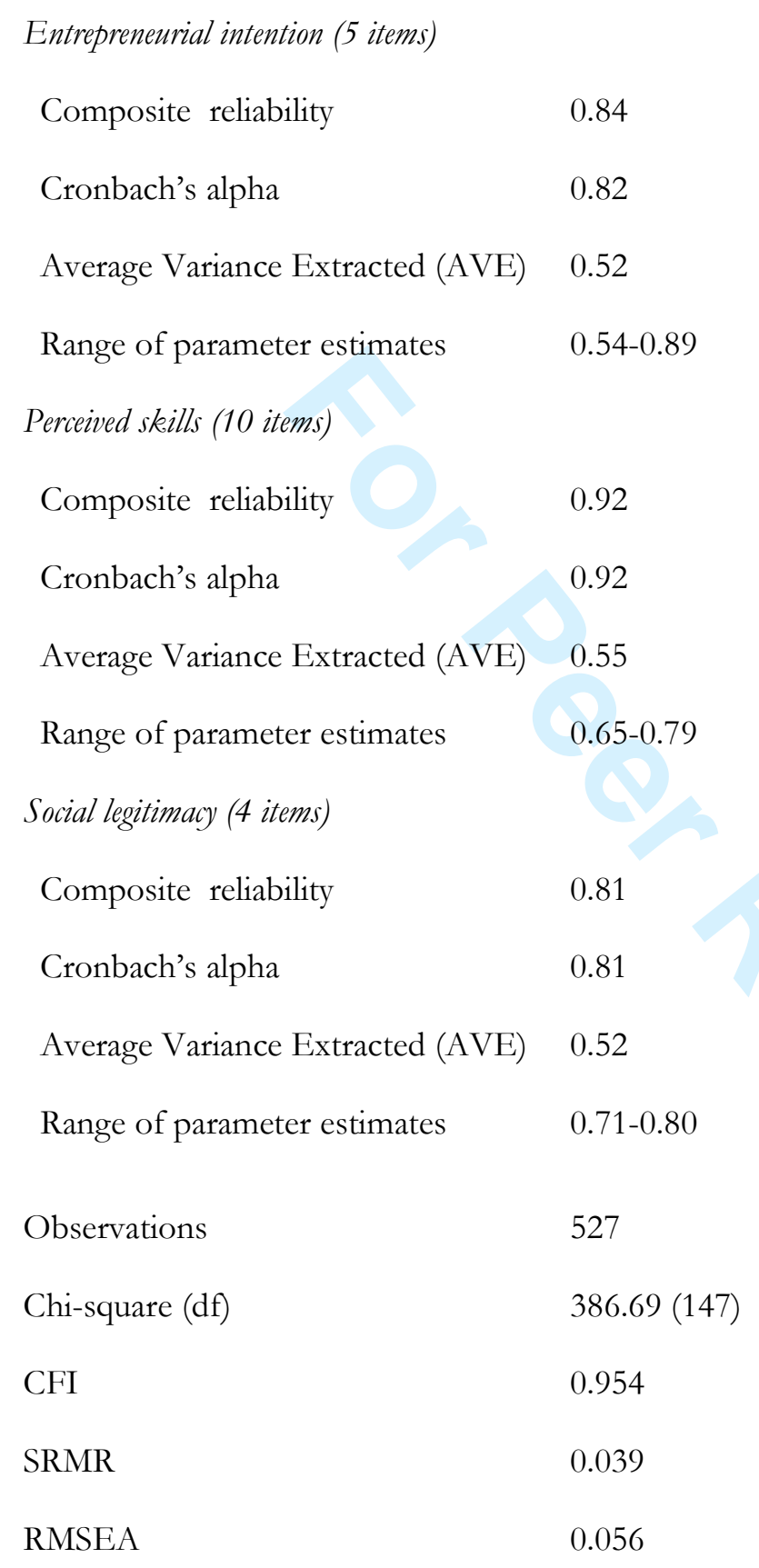


Table 2

Descriptive statistics

\begin{tabular}{|c|c|c|c|c|c|c|c|c|c|}
\hline \multirow[b]{2}{*}{ Variable } & \multirow[b]{2}{*}{ Mean } & \multirow[b]{2}{*}{$\mathrm{SD}$} & \multicolumn{2}{|c|}{ Correlations } & \multirow[b]{2}{*}{3.} & \multirow[b]{2}{*}{4.} & \multirow[b]{2}{*}{5.} & \multirow[b]{2}{*}{6.} & \multirow[b]{2}{*}{7.} \\
\hline & & & 1. & 2. & & & & & \\
\hline Entrepreneurial intention & 2.90 & 1.22 & 1 & & & & & & \\
\hline Perceived skills & 3.18 & 0.81 & 0.37 & 1 & & & & & \\
\hline Social legitimacy & 3.57 & 0.73 & 0.27 & 0.52 & 1 & & & & \\
\hline Female & $62 \%$ & & -0.20 & -0.03 & 0.01 & 1 & & & \\
\hline International student & $8 \%$ & & 0.15 & 0.12 & 0.02 & -0.05 & 1 & & \\
\hline Postgraduate student & $34 \%$ & & -0.06 & 0.08 & 0.24 & 0.10 & -0.19 & 1 & \\
\hline $\begin{array}{l}\text { Knows an entrepreneur } \\
\text { personally }\end{array}$ & $65 \%$ & & 0.27 & 0.10 & -0.03 & -0.10 & 0.08 & -0.13 & 1 \\
\hline Entrepreneurship education & $20 \%$ & & 0.36 & 0.12 & 0.08 & -0.19 & 0.21 & -0.20 & 0.17 \\
\hline
\end{tabular}

Notes: $N=527$. Pearson correlations. Coefficients equal to or greater than 0.10 are significant at the $5 \%$ level. 


\section{Table 3}

Ordinary-least-squares (OLS) regression estimates pertaining to entrepreneurial intention

\begin{tabular}{|c|c|c|c|c|c|c|}
\hline & \multicolumn{2}{|c|}{ Model 1} & \multicolumn{2}{|c|}{ Model 2} & \multicolumn{2}{|c|}{ Model 3} \\
\hline & Coefficient & SE & Coefficient & SE & Coefficient & SE \\
\hline Perceived skills & $0.49^{* * *}$ & 0.07 & $0.50^{* * *}$ & 0.07 & $0.39 * * *$ & 0.07 \\
\hline Social legitimacy & $0.18^{*}$ & 0.09 & $0.24 * *$ & 0.09 & $0.27 * * *$ & 0.08 \\
\hline Interaction: skills x legitimacy & & & $0.22^{* * *}$ & 0.07 & $0.17 * *$ & 0.06 \\
\hline Female & & & & & $-0.33 * * *$ & 0.10 \\
\hline International student & & & & & 0.18 & 0.17 \\
\hline Postgraduate student & & & & & -0.02 & 0.10 \\
\hline Knows an entrepreneur personally & & & & & $0.49 * * *$ & 0.10 \\
\hline Entrepreneurship education & & & & & $0.80^{* * *}$ & 0.13 \\
\hline Intercept & 2.91 & 0.05 & 2.84 & 0.06 & 2.58 & 0.13 \\
\hline R-squared & 0.14 & & 0.16 & & 0.31 & \\
\hline F-statistic & $47.04(2$ & 524) & $39.93(3$ & 523) & $32.74(8$, & 18) \\
\hline
\end{tabular}

Notes: $N=527$. Heteroscedasticity-robust standard errors. Perceived skills and social legitimacy meancentred.

$* p<0.05, * * p<0.01, * * * p<0.001$ (one-tailed test). 


\section{Figure 1}

Marginal effect of perceived skills on entrepreneurial intentions at different levels of social legitimacy ( $95 \%$ confidence intervals)

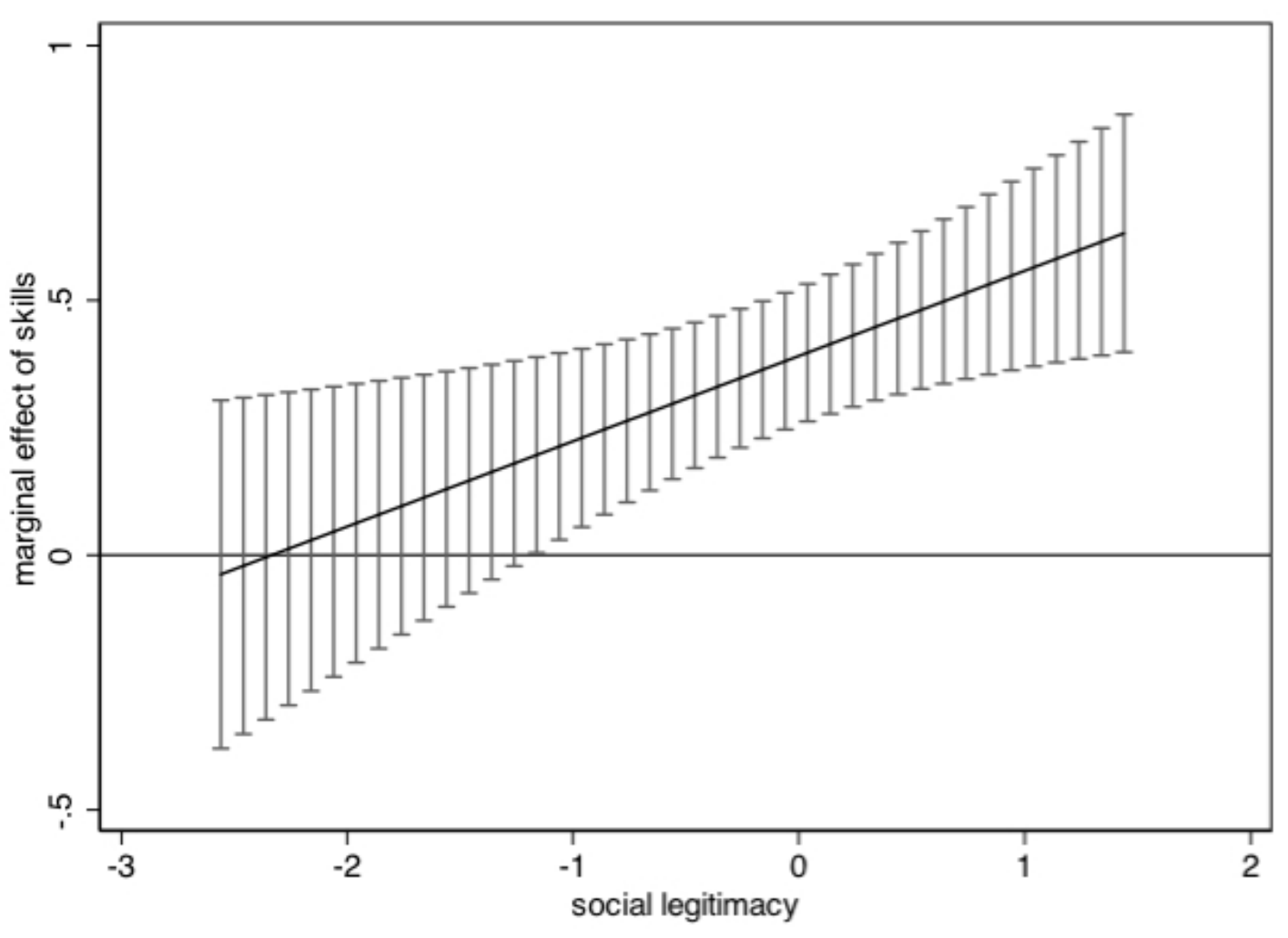

36

37

38

39

40

41

42

43

44

45

46

47

48

49

50

51

52

53

54

55

56

57

58

59

60 